\title{
Early Versus Late Tracheostomy for Patients with High and Low Cervical Spinal Cord Injuries
}

Akram H. Guirgis, ${ }^{1}$ Venugopal K. Menon, ${ }^{2}$ Neelam Suri, ${ }^{1}$ "Nilay Chatterjee, ${ }^{1}$ Emil Attallah, ${ }^{1}$ Maged Y. Saad, ${ }^{1}$ Shereen Elshaer ${ }^{3}$

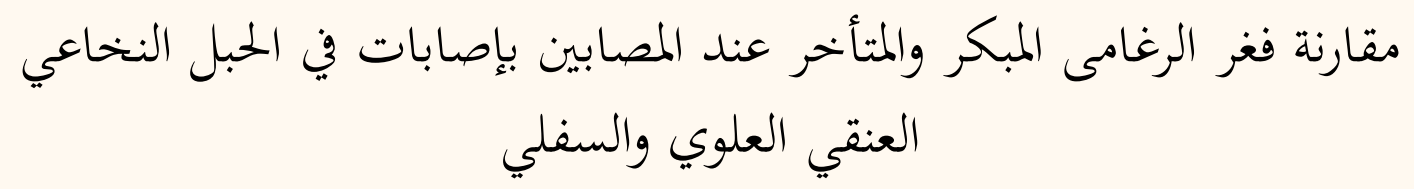

أكرم حنين جرجس، فينوجويال مينون، نيلام سورى، نيلاى شاتارجى، أميل عطا اله، ماجد يوسف سعد، شيرين الشاعر

ABSTRACT: Objectives: This study aimed to evaluate the effects of early versus late tracheostomies among patients with cervical spinal cord injuries (CSCIs). Methods: This retrospective study included 69 adult CSCI patients who underwent bedside percutaneous tracheostomies at the Intensive Care Unit of Khoula Hospital, Muscat, Oman, between January 2011 and October 2015. The tracheostomy was considered early if the procedure took place within one week of the CSCI. The impact of an early tracheostomy on patient outcomes was analysed in terms of duration of mechanical ventilation and intensive care unit (ICU) stay among patients with high (C1-C2 vertebrae) and low (C3-C7 vertebrae) CSCIs. Ventilator dependence, bradycardia episodes and surgical intervention outcomes were also examined. Results: Patients with a high CSCI who underwent an early tracheostomy spent significantly fewer days on mechanical ventilation compared to those who underwent a late tracheostomy $(9.3 \pm 7.2$ days versus $13.7 \pm 3.2$ days; $P=0.041$ ). Low CSCI patients who received an early tracheostomy also experienced significantly fewer days on mechanical ventilation compared to those undergoing a late tracheostomy $(12.1 \pm 10.4$ days versus $25.2 \pm 17.7$ days; $P=0.035$ ). Moreover, ICU mortality was significantly lower for high CSCI patients who underwent an early tracheostomy $(P=0.015)$. However, there was no association between length of ICU stay and either type of CSCI or timing of the tracheostomy procedure. Conclusion: An early tracheostomy is beneficial in reducing the duration of mechanical ventilation among patients with CSCIs, irrespective of the level of injury.

Keywords: Spinal Cord Injuries; Tracheostomy; Treatment Outcome; Mechanical Ventilation; Intensive Care Unit.

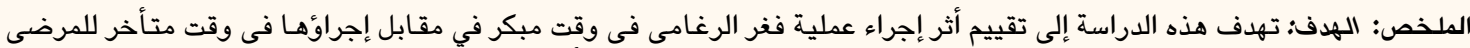

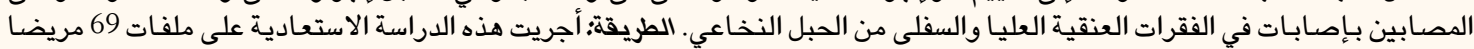

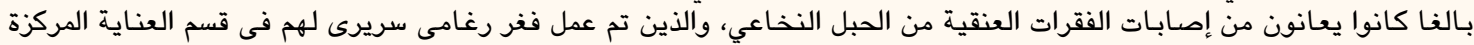

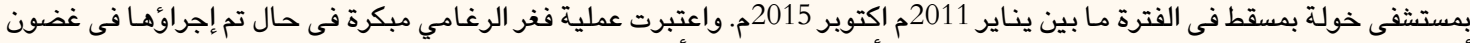

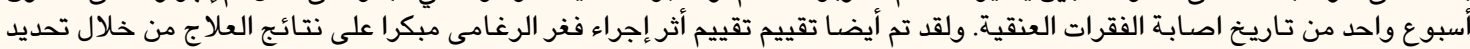

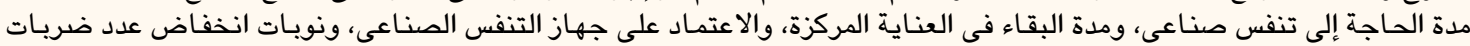

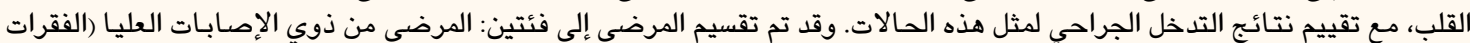

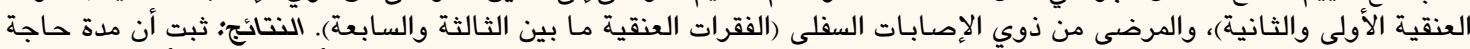

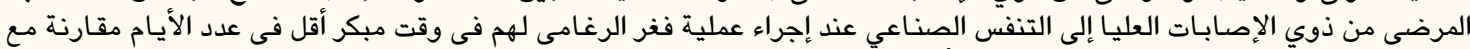

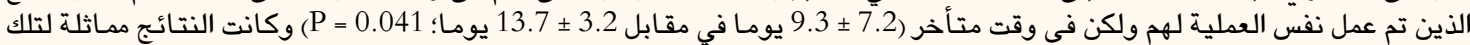

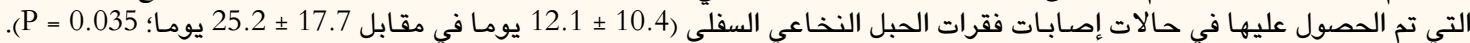

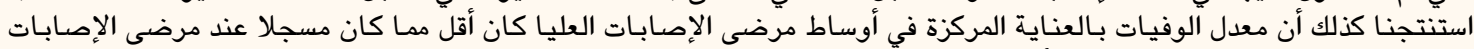

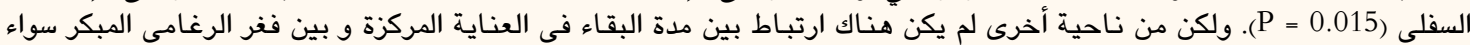

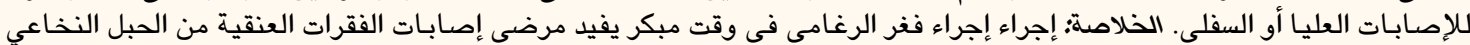

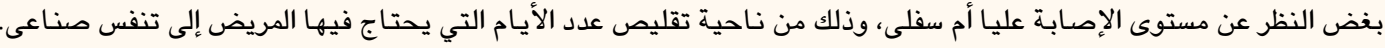
الكلمات المفتاحية: إصـابـات الحبل النخاعي؛ فغر الرغامى؛ نتائج العلاج؛ التنفس الصناعى؛ وحدة العناية المركز.

\section{AdVANCES IN KNOWLEDGE}

The current study sought to determine the ideal timing of a tracheostomy and its impact on patient outcomes, which is a subject of substantial controversy.

An early tracheostomy was found to significantly reduce the duration of mechanical ventilation in patients with both high and low cervical spinal cord injuries (CSCIs).

High CSCI patients had significantly lower mortality when undergoing an early tracheostomy compared to those receiving a late tracheostomy; however, this trend was not observed for patients with low CSCIS. 


\section{Application to Patient Care}

The findings of this study indicate that patients with high CSCIs should undergo an early tracheostomy within seven days of injury in order to reduce duration of mechanical ventilation and its sequelae. Patients with low CSCIs need to be evaluated on an individual basis regarding the decision to proceed with an early tracheostomy.

\section{$\mathrm{T}$} RACHeOSTOMies ARE AMONG THE MOST commonly performed procedures in the intensive care unit (ICU). ${ }^{1}$ The intervention is designed to improve mechanical ventilatory support by decreasing dead space, enabling trachea-bronchial clearance and avoiding the sequelae of prolonged orotracheal intubation. Hence, a tracheostomy facilitates early weaning from mechanical ventilation, shortens the length of time that patients must remain under sedation and reduces associated complications. ${ }^{2}$ However, a tracheostomy is an invasive procedure and, although rare, can cause tracheal stenosis or other complications. $^{3}$ Patients with cervical spinal cord injuries (CSCIs) have a high incidence (40-70\%) of respiratory complications, such as atelectasis and pneumonia. ${ }^{4}$ Fractures to the upper cervical spine (C1-C2 vertebrae) are considered high injuries, while fractures to the rest of the cervical spine are classified as low injuries. ${ }^{5,6}$ In patients with a CSCI, a neurological injury at or above the $\mathrm{C} 4$ vertebrae and haematoma-like changes in the spinal cord revealed via magnetic resonance imaging predict the need for an early tracheostomy. ${ }^{\text {? }}$

Although tracheostomies play a vital role in the airway management of CSCI patients, the ideal timing of the procedure remains a subject of substantial debate. ${ }^{8}$ Long-term dependence on mechanical ventilation is common in patients with high CSCIs. ${ }^{9}$ The conventional practice is to perform a tracheostomy if the anticipated duration of mechanical ventilation exceeds two weeks. ${ }^{10}$ In 1989, Plummer et al. stated that patients requiring mechanical ventilation for up to 10 days should be endotracheally intubated, whereas a tracheostomy was favoured when the predicted course of mechanical ventilation was greater than 21 days. ${ }^{11}$ However, evidence for this practice is limited and a defined pathway for the airway management of CSCI patients does not exist. ${ }^{10,12}$ The broad consensus among published studies is that an early tracheostomy is associated with fewer days in the ICU and a shorter duration of mechanical ventilation, although there are divergent findings regarding the impact of this procedure on rates of pneumonia or mortality. ${ }^{13-15}$ This study aimed to assess the impact of an early versus late tracheostomy among patients with high $(\mathrm{C} 1-\mathrm{C} 2)$ and low (C3-C7) CSCIs. To the best of the authors' knowledge, this study is the first to compare early and late tracheostomies among patients with high and low CSCIs.

\section{Methods}

This retrospective study included 69 adult patients with CSCIs who underwent a bedside percutaneous tracheostomy in the ICU of Khoula Hospital, Muscat, Oman, between January 2011 and October 2015. Only patients aged between 18-60 years old with an anticipated period of mechanical ventilation of $>14$ days and an initial Acute Physiology and Chronic Health Evaluation II score of $>25$ were included. The exclusion criteria consisted of patients with an anatomical deformity of the neck, those who had had an earlier tracheostomy and those with active coagulopathy (defined as a platelet count $<50,000 / c c$, an activated partial thromboplastin or prothrombin time $>1.5$ or bleeding time more than twice the normal range) or a soft tissue infection of the neck. In addition, patients with fraction of inspired oxygen requirements of $>0.7$ or a positive end-expiratory pressure of $>12$ were excluded. A tracheostomy was considered early if it was performed within seven days of injury; when performed from day eight onwards, it was considered a late tracheostomy. The level of CSCI was classified as high when the injury involved the first or second cervical vertebrae $(\mathrm{C} 1-\mathrm{C} 2$ vertebrae) and low if the injury involved the rest of the cervical spine (C3-C7 vertebrae). An injury severity score (ISS) of $>30$ and a sepsis-related organ failure assessment score of $>11$ was considered severe.

The primary objective of the study was to evaluate the impact of an early versus late tracheostomy on outcomes in terms of duration of mechanical ventilation and ICU stay. In addition, the impact in terms of ventilator dependence, bradycardia episodes and surgical intervention outcomes was analysed. The effects of an early tracheostomy were compared with those of a late tracheostomy separately for both high and low CSCI patients. In addition, the impact of an early tracheostomy was compared between high and low CSCI patients. The Statistical Package for the Social Sciences (SPSS), Version 16.0 (IBM Corp., Chicago, Illinois, USA) was used for data analysis. Data were expressed as means and standard deviations or as numbers and percentages. Non-parametric data were compared using Pearson's Chi-squared or Fisher's exact tests, as applicable. Continuous variables were compared using Student's t-test. A $P$ value of $<0.050$ was considered statistically significant. 
Table 1: Comparison of characteristics of patients with cervical spinal cord injuries undergoing tracheostomies according to level of injury $(\mathrm{N}=69)$

\begin{tabular}{|c|c|c|c|}
\hline \multirow[t]{2}{*}{ Characteristic } & \multicolumn{2}{|c|}{ n (\%) } & \multirow{2}{*}{$\begin{array}{c}P \\
\text { value }\end{array}$} \\
\hline & $\begin{array}{l}\text { High CSCI } \\
(\mathrm{n}=45)\end{array}$ & $\begin{array}{l}\text { Low CSCI } \\
(\mathrm{n}=24)\end{array}$ & \\
\hline $\begin{array}{l}\text { Mean age in years } \\
\pm \mathrm{SD}\end{array}$ & $32.4 \pm 8.5$ & $33.7 \pm 7.8$ & 0.532 \\
\hline $\begin{array}{l}\text { Male-to-female } \\
\text { ratio }\end{array}$ & $34: 11$ & $20: 4$ & 0.550 \\
\hline $\begin{array}{l}\text { Mean ICU stay in } \\
\text { days } \pm \text { SD }\end{array}$ & $20.8 \pm 7.4$ & $22.3 \pm 5.5$ & 0.383 \\
\hline $\begin{array}{l}\text { Mean mechanical } \\
\text { ventilation duration } \\
\text { in days } \pm S D\end{array}$ & $10.8 \pm 7.9$ & $15.3 \pm 13.4$ & 0.089 \\
\hline Deaths & $7(15.6)$ & $4(16.7)$ & 0.945 \\
\hline $\begin{array}{l}\text { Ventilator } \\
\text { dependence }\end{array}$ & $2(4.4)$ & $4(16.7)$ & 0.417 \\
\hline Severe cord trauma & $5(11.1)$ & $9(37.5)$ & $0.041^{*}$ \\
\hline Bradycardia & $3(6.7)$ & $5(20.8)$ & 0.116 \\
\hline Severe SOFA score & $26(57.8)$ & $15(62.5)$ & 0.799 \\
\hline Severe ISS & $29(64.4)$ & $15(62.5)$ & 0.872 \\
\hline $\begin{array}{l}\text { Associated severe } \\
\text { head injury }\end{array}$ & $1(2.2)$ & $2(8.3)$ & 0.546 \\
\hline Early tracheostomy & $32(71.1)$ & $19(79.2)$ & 0.571 \\
\hline Late tracheostomy & $13(28.9)$ & $5(20.8)$ & 0.571 \\
\hline
\end{tabular}

The protocol of this study was approved by the Institutional Ethical Committee of Khoula Hospital. Informed consent was obtained from each patient or their surrogate decision-maker before the tracheostomy was performed.

\section{Results}

Of the 69 CSCI patients who underwent bedside percutaneous tracheostomies during the study period, 45 (65.2\%) had high CSCIs and 24 (34.8\%) had low CSCIs. The demographic and clinical characteristics of these patients were comparable [Table 1]. During the course of their stay in the ICU, the following complications were observed: pneumonia $(n=11$; $15.9 \%)$, dependency on inotropes $(\mathrm{n}=8 ; 11.6 \%)$, sepsis $(\mathrm{n}=6 ; 8.7 \%)$, ventilator-associated pneumonia $(\mathrm{n}=4$; $5.8 \%)$, gastrointestinal haemorrhage $(\mathrm{n}=3 ; 4.8 \%)$, severe bradycardia $(\mathrm{n}=3 ; 4.8 \%)$, respiratory arrest $(\mathrm{n}=3 ; 4.8 \%)$, abdominal compartment syndrome $(\mathrm{n}=1 ; 1.4 \%)$ and abdominal haemorrhage $(\mathrm{n}=1 ; 1.4 \%)$.

Among patients with high CSCIs, the duration of mechanical ventilation was significantly reduced
Table 2: Comparison of characteristics of patients with high cervical spinal cord injuries undergoing tracheostomies according to type of tracheostomy $(\mathrm{N}=45)$

\begin{tabular}{|c|c|c|c|}
\hline Characteristic & & & $P$ \\
\hline & $\begin{array}{c}\text { Early } \\
\text { tracheostomy } \\
(\mathbf{n}=32)\end{array}$ & $\begin{array}{c}\text { Late } \\
\text { tracheostomy } \\
(\mathbf{n}=13)\end{array}$ & \\
\hline $\begin{array}{l}\text { Mean age in } \\
\text { years } \pm S D\end{array}$ & $31.7 \pm 8.3$ & $35.9 \pm 9.2$ & 0.2 \\
\hline $\begin{array}{l}\text { Male-to-female } \\
\text { ratio }\end{array}$ & $24: 8$ & $10: 3$ & \\
\hline $\begin{array}{l}\text { Mean ICU stay } \\
\text { in days } \pm \text { SD }\end{array}$ & $19.1 \pm 32.7$ & $18.2 \pm 5.2$ & \\
\hline $\begin{array}{l}\text { Mean } \\
\text { mechanical } \\
\text { ventilation } \\
\text { duration in } \\
\text { days } \pm \text { SD }\end{array}$ & $9.3 \pm 7.2$ & $13.7 \pm 3.2$ & 0.0 \\
\hline Deaths & $2(6.3)$ & $5(38.5)$ & 0.01 \\
\hline $\begin{array}{l}\text { Ventilator } \\
\text { dependence }\end{array}$ & $2(6.3)$ & $0(0.0)$ & 0.5 \\
\hline $\begin{array}{l}\text { Severe cord } \\
\text { trauma }\end{array}$ & $3(9.4)$ & $2(15.4)$ & \\
\hline Bradycardia & $1(3.1)$ & $2(15.4)$ & 0.1 \\
\hline $\begin{array}{l}\text { Severe SOFA } \\
\text { score }\end{array}$ & $19(59.4)$ & $7(53.8)$ & 0.7 \\
\hline Severe ISS & $23(71.9)$ & $6(46.2)$ & 0.1 \\
\hline $\begin{array}{l}\text { Associated } \\
\text { severe head } \\
\text { injury }\end{array}$ & $1(3.1)$ & $0(0.0)$ & \\
\hline
\end{tabular}

$S D=$ standard deviation; $I C U$ = intensive care unit SOFA = sequential organ failure assessment score; ISS = injury severity score.

*Significant at $P<0.050$.

for those who had received an early tracheostomy compared to those who had undergone a late tracheostomy (9.3 \pm 7.2 days versus $13.7 \pm 3.2$ days; $P=0.041)$. However, no significant difference was found in terms of length of ICU stay between these groups $(P=0.982)$. High CSCI patients undergoing an early tracheostomy demonstrated significantly lower mortality compared to those with late tracheostomy (6.3\% versus $38.5 \% ; P=0.015)$ [Table 2]. The duration of mechanical ventilation was also significantly reduced for patients with low CSCIs who had undergone an early tracheostomy compared to those with low CSCIs who had undergone a late tracheostomy (12.1 \pm 10.4 days versus $25.2 \pm 17.7$ days; $P=0.035)$; however, patients with low CSCI undergoing an early tracheostomy did not have a significantly reduced mortality rate $(15.8 \%$ versus $20.0 \% ; P=0.999)$ [Table 3].

In comparing the impact of an early tracheostomy between high and low CSCI patients, high CSCI patients had a reduced ICU stay $(19.1 \pm 32.7$ days versus $23.4 \pm 27.8$ days) and duration of mechanical ventilation $(9.3 \pm 7.2$ days versus $12.1 \pm 10.4$ days $)$; 
Table 3: Comparison of characteristics of patients with low cervical spinal cord injuries undergoing tracheostomies according to type of tracheostomy $(\mathrm{N}=24)$

\begin{tabular}{|c|c|c|c|}
\hline \multirow[t]{2}{*}{ Characteristic } & \multicolumn{2}{|c|}{ n (\%) } & \multirow{2}{*}{$\begin{array}{c}P \\
\text { value }\end{array}$} \\
\hline & $\begin{array}{c}\text { Early } \\
\text { tracheostomy } \\
(\mathbf{n}=19)\end{array}$ & $\begin{array}{c}\text { Late } \\
\text { tracheostomy } \\
(\mathbf{n}=5)\end{array}$ & \\
\hline $\begin{array}{l}\text { Mean age in } \\
\text { years } \pm S D\end{array}$ & $32.7 \pm 7.8$ & $35.8 \pm 7$ & 0.414 \\
\hline $\begin{array}{l}\text { Male-to-female } \\
\text { ratio }\end{array}$ & $16: 3$ & $4: 1$ & 0.999 \\
\hline $\begin{array}{l}\text { Mean ICU stay } \\
\text { in days } \pm \mathrm{SD}\end{array}$ & $23.4 \pm 27.8$ & $33.6 \pm 31.8$ & 0.479 \\
\hline $\begin{array}{l}\text { Mean } \\
\text { mechanical } \\
\text { ventilation } \\
\text { duration in days } \\
\pm \mathrm{SD}\end{array}$ & $12.1 \pm 10.4$ & $25.2 \pm 17.7$ & $0.035^{*}$ \\
\hline Deaths & $3(15.8)$ & $1(20.0)$ & 0.999 \\
\hline $\begin{array}{l}\text { Ventilator } \\
\text { dependence }\end{array}$ & $3(15.8)$ & $1(20.0)$ & 0.999 \\
\hline $\begin{array}{l}\text { Severe cord } \\
\text { trauma }\end{array}$ & $7(36.8)$ & $2(40.0)$ & 0.999 \\
\hline Bradycardia & $4(21.1)$ & $1(20.0)$ & 0.999 \\
\hline $\begin{array}{l}\text { Severe SOFA } \\
\text { score }\end{array}$ & $12(63.2)$ & $3(60.0)$ & 0.999 \\
\hline Severe ISS & $11(57.9)$ & $4(80.0)$ & 0.614 \\
\hline $\begin{array}{l}\text { Associated } \\
\text { severe head } \\
\text { injury }\end{array}$ & $2(10.5)$ & $0(0.0)$ & 0.999 \\
\hline
\end{tabular}

$S D=$ standard deviation; $I C U=$ intensive care unit; $S O F A=$ sequential organ failure assessment score; ISS = injury severity score.

*Significant at $P<0.050$.

however, these associations were not significant $(P=0.568$ and 0.114 , respectively) [Table 4$]$. No significant differences were observed in bradycardia incidence or ventilator dependence between patients undergoing early tracheostomies compared to those receiving late tracheostomies, irrespective of the anatomical level of injury. Surgical intervention also had no impact on duration of mechanical ventilation or ICU stay, regardless of the level of injury.

\section{Discussion}

Patients with a CSCI have a substantial risk of developing respiratory compromise, particularly those with a high or complete spinal cord injury. ${ }^{16}$ This study evaluated the effect of an early tracheostomy on patients with CSCIs; the results demonstrated the benefit of an early tracheostomy in terms of reduced duration of mechanical ventilation, irrespective of the anatomical level of the CSCI. However, length of ICU stay, ventilator dependence and bradycardia incidence
Table 4: Comparison of characteristics of patients with cervical spinal cord injuries undergoing early tracheostomies according to level of injury $(\mathrm{N}=51)$

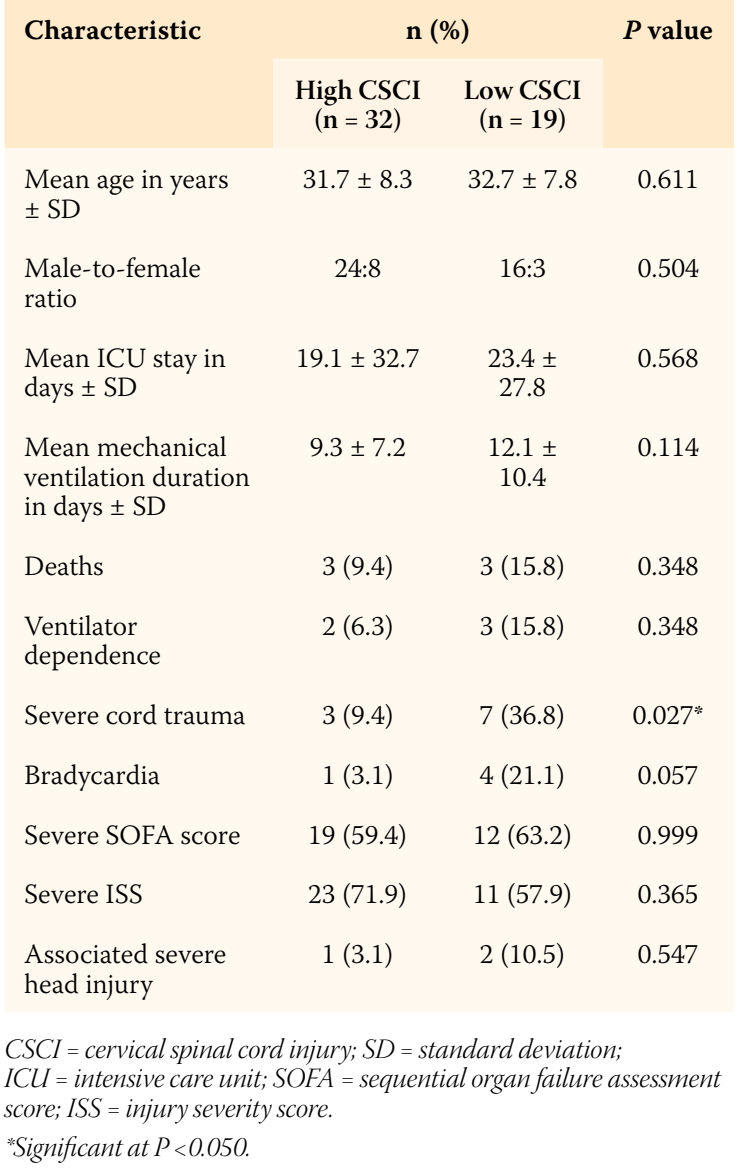

were not significantly affected by the timing of the intervention.

In the ICU, a practical decision regarding the optimal timing of a tracheostomy in CSCI patients is often based on the perceived risk-to-benefit ratio and the clinical indications of the procedure. An early tracheostomy has been reported to lower complication rates, particularly tracheal granulomas and stenosis. ${ }^{14}$ In a systematic review, Griffiths et al. found that an early tracheostomy significantly reduced the duration of mechanical ventilation and the length of stay in the ICU; however, there was no impact on mortality or the incidence of pneumonia. ${ }^{17}$ In comparison, Rumbak et al. reported that a tracheostomy performed within 48 hours of injury significantly decreased rates of mortality and pneumonia as well as the duration of mechanical ventilation and ICU stay. ${ }^{13}$ A meta-analysis by Dunham et al. indicated that an early tracheostomy resulted in patients with severe head injuries being more rapidly weaned off of mechanical ventilation, although survival rates did not change. ${ }^{18}$ De Leyn et al. demonstrated that a tracheostomy performed within seven days of the injury shortened the duration of mechanical ventilation and ICU stay in adult trauma 
victims ${ }^{19}$ In another meta-analysis of early versus late tracheostomies, Liu et al. reported that the former significantly decreased ICU stays but did not influence mortality; similar results were presented by Jeon et al. ${ }^{15,20}$ Leelapattana et al. also found that an early tracheostomy resulted in fewer days on mechanical ventilation and a shorter hospital stay. ${ }^{21}$

A high CSCI is invariably associated with respiratory compromise and higher mortality. ${ }^{22}$ In a retrospective analysis of 178 patients, Harrop et al. found that all patients with grade A injuries as classified by the American Spinal Injury Association at the C2 and C3 vertebrae needed tracheostomies, whereas no patients with $\mathrm{C} 8$ injuries required the procedure. ${ }^{8}$ According to a nationwide study of Finnish patients with fatal cervical spine injuries between 1987 and 2010, the majority of high CSCI patients who were $<60$ years old died within 24 hours of injury. ${ }^{6}$ The present study found that a tracheostomy performed within seven days of injury in CSCI patients resulted in significantly reduced duration of mechanical ventilation regardless of the anatomical level of injury. Although the current study did not show an overall reduction in the length of ICU stay following an early tracheostomy, patients with a low CSCI stayed for a longer length of time in the ICU on average. An early tracheostomy significantly reduced mortality rates among patients with high CSCIs, although this trend was not observed for the low CSCI group; as a result, an early tracheostomy is recommended for patients with high CSCIs although patients with low CSCIs should be evaluated on a case-by-case basis.

Tracheostomies offer numerous advantages over endotracheal intubation, such as reduced airway resistance, improved pulmonary hygiene and diminished work of breathing, thereby enabling easier and earlier weaning from mechanical ventilation..$^{23,24}$ A fenestrated tracheostomy also allows for phonation, enabling the patient to communicate vocally; this has been shown to improve both medical and psychological outcomes among patients with neurological injuries. ${ }^{25,26}$ Factors which can influence the decision to perform a tracheostomy in CSCI patients include the presence of a complete CSCI, the anatomical level of injury, the patient's Glasgow Coma Scale score and ISS and the presence of an associated thoracic injury. ${ }^{27}$ A bedside percutaneous tracheostomy is currently the standard procedure for patients requiring mechanical ventilation. ${ }^{28}$ In low CSCIs (C5-T1 vertebra), a catastrophic loss of airway control often negates the benefits of treatment. ${ }^{29}$ Hassid et al. affirmed that an immediate thorough evaluation for respiratory failure is necessary among low CSCI patients, regardless of the severity of the injury; they recommended early intubation in these patients and found that half of incomplete CSCI patients would eventually require a tracheostomy. ${ }^{29}$

This retrospective study had several limitations. The analysis focused on a moderate number of patients from a single centre with a limited follow-up period; therefore, the impact of an early tracheostomy on long-term mortality or survival benefits could not be assessed. The total length of hospital stay was also not considered. Moreover, the impact of operator skill in performing the tracheostomy may have affected outcomes. Future studies should be prospective in nature and include a higher number of patients from different centres, more rigorous inclusion and exclusion criteria and a longer follow-up period in order to determine the replicability of the findings observed in the present study.

\section{Conclusion}

A tracheostomy performed within seven days of injury significantly reduced the duration of mechanical ventilation among CSCI patients, irrespective of the anatomical level of injury. However, there was no association between length of ICU stay and either the timing of the tracheostomy or level of injury, although patients with a low CSCI spent a longer time in the ICU on average. Mortality was significantly lower among high CSCI patients who underwent an early tracheostomy, although this was not the case for patients with low CSCIs. Based on these findings, it is recommended that all patients with high CSCIs be considered for an early tracheostomy, while those with a low CSCI should be evaluated on an individual basis.

\section{CONFLICT OF INTEREST}

The authors declare no conflicts of interest.

\section{FUNDING}

No funding was received for this study.

\section{ACKNOWLEDGEMENTS}

This study was previously presented as a poster abstract at the European Society of Intensive Care Medicine LIVES 2016 Conference in Milan, Italy, on 1-5 October 2016. An abstract of the poster was published in Intensive Care Medicine Experimental in 2016 (Vol. 4, Iss. S1, P. A307). 


\section{References}

1. Rana S, Pendem S, Pogodzinski MS, Hubmayr RD, Gajic O. Tracheostomy in critically ill patients. Mayo Clin Proc 2005; 80:1632-8. doi: 10.4065/80.12.1632

2. Jaeger JM, Littlewood KA, Durbin CG Jr. The role of tracheostomy in weaning from mechanical ventilation. Respir Care 2002; 47:469-80.

3. Dempsey GA, Morton B, Hammell C, Williams LT, Tudur Smith C, Jones T. Long-term outcome following tracheostomy in critical care: A systematic review. Crit Care Med 2016; 44:617-28. doi: 10.1097/CCM.0000000000001382.

4. Jackson AB, Groomes TE. Incidence of respiratory complications following spinal cord injury. Arch Phys Med Rehabil 1994; 75:270-5. doi: 10.1016/0003-9993(94)90027-2.

5. Herkowitz HN, Garfin SR, Eismont FJ, Bell GR, Balderston RA Rothman-Simeone: The Spine, 6th ed. Philadelphia, Pennsylvania, USA: Saunders , 2011. Pp. 1307-32.

6. Thesleff T, Niskakangas T, Luoto TM, Öhman J, Ronkainen A Fatal cervical spine injuries: A Finnish nationwide registerbased epidemiologic study on data from 1987 to 2010. Spine J 2016; 16:918-26. doi: 10.1016/j.spinee.2015.11.054.

7. Tanaka J, Yugue I, Shiba K, Maeyama A, Naito M. A study of risk factors for tracheostomy in patients with a cervical spinal cord injury. Spine (Phila Pa 1976) 2016; 41:764-71. doi: 10.1097/BRS.0000000000001317.

8. Harrop JS, Sharan AD, Scheid EH Jr, Vaccaro AR, Przybylski GJ Tracheostomy placement in patients with complete cervical spinal cord injuries: American Spinal Injury Association Grade A. J Neurosurg 2004; 100:20-3. doi: 10.3171/spi.2004. 100.1 .0020 .

9. Como JJ, Sutton ER, McCunn M, Dutton RP, Johnson SB, Aarabi B, et al. Characterizing the need for mechanical ventilation following cervical spinal cord injury with neurologic deficit. J Trauma 2005; 59:912-16. doi: 10.1097/01. ta.0000187660.03742. a6.

10. McWhorter AJ. Tracheotomy: Timing and techniques. Cur Opin Otolaryngol Head Neck Surg 2003; 11:473-9. doi: 10.1097 /00020840-200312000-00012.

11. Plummer AL, Gracey DR. Consensus conference on artificial airways in patients receiving mechanical ventilation. Chest 1989; 96:178-80. doi: 10.1378/chest.96.1.178.

12. Littlewood K, Durbin CG Jr. Evidenced-based airway management. Respir Care 2001; 46:1392-405.

13. Rumbak MJ, Newton M, Truncale T, Schwartz SW, Adams JW, Hazard PB. A prospective, randomized, study comparing early percutaneous dilational tracheotomy to prolonged translaryngeal intubation (delayed tracheotomy) in critically ill medical patients. Crit Care Med 2004; 32:1689-94. doi: 10.1097/01.CCM.0000134835.05161.B6.

14. Romero J, Vari A, Gambarrutta C, Oliviero A. Tracheostomy timing in traumatic spinal cord injury. Eur Spine J 2009, 18:1452-7. doi: 10.1007/s00586-009-1097-3

15. Liu CC, Livingstone D, Dixon E, Dort JC. Early versus late tracheostomy: A systematic review and meta-analysis. Otolaryngol Head Neck Surg 2015; 152:219-27. doi: 10.1177 /0194599814561606.
16. Aarabi B, Harrop JS, Tator $\mathrm{CH}$, Alexander $\mathrm{M}$, Dettori JR, Grossman RG, et al. Predictors of pulmonary complications in blunt traumatic spinal cord injury. J Neurosurg Spine 2012; 17:38-45. doi: 10.3171/2012.4.AOSPINE1295.

17. Griffiths J, Barber VS, Morgan L, Young JD. Systematic review and meta-analysis of studies of the timing of tracheostomy in adult patients undergoing artificial ventilation. BMJ 2005; 330:1243. doi: 10.1136/bmj.38467.485671.E0.

18. Dunham CM, Ransom KJ. Assessment of early tracheostomy in trauma patients: A systematic review and meta-analysis. Am Surg 2006; 72:276-81.

19. De Leyn P, Bedert L, Delcroix M, Depuydt P, Lauwers G, Sokolov Y, et al. Tracheotomy: Clinical review and guidelines. Eur J Cardiothorac Surg 2007; 32:412-21. doi: 10.1016/j.ejcts. 2007.05.018

20. Jeon YT, Hwang JW, Lim YJ, Lee SY, Woo KI, Park HP. Effect of tracheostomy timing on clinical outcome in neurosurgical patients: Early versus late tracheostomy. J Neurosurg Anesthesiol 2014; 26:22-6. doi: 10.1097/ANA.0b013e31829770a0.

21. Leelapattana P, Fleming JC, Gurr KR, Bailey SI, Parry N, Bailey CS. Predicting the need for tracheostomy in patients with cervical spinal cord injury. J Trauma Acute Care Surg 2012; 73:880-4. doi: 10.1097/TA.0b013e318251fb34.

22. Shao J, Zhu W, Chen X, Jia L, Song D, Zhou X, et al. Factors associated with early mortality after cervical spinal cord injury. I Spinal Cord Med 2011; 34:555-62. doi: 10.1179 /2045772311Y.0000000024

23. Davis K Jr, Campbell RS, Johannigman JA, Valente JF, Branson RD. Changes in respiratory mechanics after tracheostomy. Arch Surg 1999; 134:59-62. doi: 10.1001/archsurg.134.1.59.

24. Diehl JL, El Atrous S, Touchard D, Lemaire F, Brochard L. Changes in the work of breathing induced by tracheotomy in ventilator-dependent patients. Am J Respir Crit Care Med 1999; 159:383-8. doi: 10.1164/ajrccm.159.2.9707046.

25. Lanza DC, Parnes SM, Koltai PJ, Fortune JB. Early complications of airway management in head-injured patients. Laryngoscope 1990; 100:958-61. doi: 10.1288/00005537-199009000-00009.

26. Boyd SW, Benzel EC. The role of early tracheotomy in the management of the neurosurgical patient. Laryngoscope 1992; 102:559-62. doi: 10.1288/00005537-199205000-00015.

27. Jones TS, Burlew CC, Johnson JL, Jones E, Kornblith LZ, Biffl WL, et al. Predictors of the necessity for early tracheostomy in patients with acute cervical spinal cord injury: A 15-year experience. Am J Surg 2015; 209:363-8. doi: 10.1016/j. amjsurg.2014.07.016

28. Kornblith LZ, Burlew CC, Moore EE, Haenel JB, Kashuk JL, Biffl WL, et al. One thousand bedside percutaneous tracheostomies in the surgical intensive care unit: Time to change the gold standard. J Am Coll Surg 2011; 212:163-70. doi: 10.1016/j.jamcollsurg.2010.09.024.

29. Hassid VJ, Schinco MA, Tepas JJ, Griffen MM, Murphy TL, Frykberg ER, et al. Definitive establishment of airway control is critical for optimal outcome in lower cervical spinal cord injury. J Trauma 2008; 65:1328-32. doi: 10.1097/ TA.0b013e31818d07e4. 